\title{
Equipment failure: conducts of nurses and implications for patient safety
}

\author{
Falhas de equipamentos: condutas dos enfermeiros e implicações na segurança do paciente \\ Fallas de equipos: conducta de los enfermeros e implicaciones para la seguridad del paciente
}

\section{Gabriella da Silva Rangel Ribeiro', Rafael Celestino da Silva', Márcia de Assunção Ferreira', Grazielle Rezende da Silva', Juliana Faria Campos', Bianca Ribeiro Porto de Andrade' \\ 'Universidade Federal do Rio de Janeiro, Anna Nery School of Nursing. Rio de Janeiro, Brazil.}

How to cite this article:
Ribeiro GSR, Silva RC, Ferreira MA, Silva GR, Campos JF, Andrade BRP. Equipment failure:
conducts of nurses and implications for patient safety. Rev Bras Enferm [Internet]. 2018;71(4):1832-40.
DOI: http://dx.doi.org/10.1590/0034-7167-2016-0547

Submission: 11-16-2016 Approval: 07-09-2017

\section{ABSTRACT}

Objectives: To identify equipment failures during handling by nurses and analyze the conduct of the professionals when these failures occur. Methods: Descriptive, exploratory and qualitative study, whose field was the intensive care unit of a public institution, and the participants were day nurses that worked providing direct care to patients. Data were produced in 2014 through systematic observation and interviews and were examined with thick description and content analysis. Results: The outcomes evinced the inadequate functioning of infusion bombs, users' errors related to the design of equipment and problems with batteries of artificial fans. These failures related to the management of equipment in the unit. Final considerations: It is necessary to strengthen the monitoring systems of safety conditions of equipment in intensive nursing care to prevent incidents. Descriptors: Critical Care; Biomedical Technology; Patient Safety; Nursing Care; Equipment Safety.

\section{RESUMO}

Objetivo: Identificar as falhas dos equipamentos durante o seu manejo pelo enfermeiro e analisar suas condutas diante de tais falhas. Método: Pesquisa descritivo-exploratória, qualitativa, cujo campo foi a Unidade de Terapia Intensiva de uma instituição pública, e os participantes, enfermeiros diurnos atuantes na assistência direta ao paciente. Os dados foram produzidos no ano de 2014, por meio de observação sistemática e entrevista, e posteriormente submetidos a análise por descrição densa e de conteúdo. Resultados: Evidenciaram-se o funcionamento inadequado de bombas infusoras, os erros do usuário relacionados ao desenho do equipamento e problemas com baterias de ventiladores artificiais. Essas falhas identificadas têm relação com a gestão dos equipamentos da unidade. Considerações finais: É preciso fortalecer os sistemas de vigilância das condições de segurança dos equipamentos no cuidado intensivo de enfermagem, a fim de se prevenir a ocorrência de incidentes.

Descritores: Terapia Intensiva; Tecnologia Biomédica; Segurança do Paciente; Cuidados de Enfermagem; Segurança de Equipamentos.

\section{RESUMEN}

Objetivo: Identificar las fallas de equipos mientras son utilizados por enfermeros, y analizar sus conductas ante tales fallas. Método: Estudio descriptivo-exploratorio, cualitativo, realizado en la Unidad de Terapia Intensiva de una institución pública. Participaron enfermeros de turno diurno, actuantes en la atención directa del paciente. Los datos fueron obtenidos en el año 2014 a través de observación sistemática y entrevista. Posteriormente, fueron sometidos a análisis por descripción densa y de contenido. Resultados: Se evidenció funcionamiento inadecuado de bombas de infusión, errores del usuario relacionados al diseño del equipo, problemas con baterías de ventiladores artificiales. Las fallas identificadas están relacionadas a la gestión de los equipos de la unidad. Consideraciones finales: Es necesario fortalecer los sistemas de vigilancia en las condiciones de seguridad de equipos en el cuidado intensivo de enfermería, a fin de prevenir la ocurrencia de incidentes.

Descriptores: Cuidados Críticos; Tecnología Biomédica; Seguridad del Paciente; Atención de Enfermería; Seguridad de Equipos. 


\section{INTRODUCTION}

Recognition of risk of incidents related to the use of equipment in health care which compromise patient safety is a necessity for professionals who work in this area, especially nurses, because of the fast incorporation of technologies in the care they provide. The magnitude of the issue of incidents involving equipment and potential harm to patients, mainly in intensive care units (ICUs), has been disseminated in an attempt to warn the healthcare community about the evaluation of these risks to help formulate new measures that favor safety in the use of equipment ${ }^{(1-5)}$.

An integrative review showed that the causes for the occurrence of adverse effects involving technologies in intensive care refer to the apparatuses themselves, problems in their functioning, mistakes by the healthcare team, such as inappropriate use, and other issues, for instance, the violation of the proper procedures to handle the tools ${ }^{(6)}$. These causes were mentioned in other studies ${ }^{(1-3)}$, in which two reasons were predominant in incidents with equipment. The first one was the inappropriate use of equipment ${ }^{(1,7)}$. A study about the use of intermittent pneumatic compression devices in critical patients revealed errors in the application in $49 \%$ of the 976 observations made in 108 patients, mainly in placing the sleeves in the $\operatorname{legs}^{(3)}$. Another investigation, which focused on the evaluation of programmed adjustments in infusion pumps and its comparison with medical prescriptions, pointed discrepancies ranging from $24.3 \%$ to $42.4 \%{ }^{(5)}$.

The second cause, object of the present study, was error in the fabrication process, which occurred in the design and production phases, that is, conceptual mistakes or manufacture out of specification. In the investigation, these mistakes are understood as equipment failure, which is considered an important factor associated with harm to patients ${ }^{(8-9)}$. These damages were reported in a survey carried out in a safety incident notification database, in which incidents provoked by defective equipment and equipment malfunction were responsible for 537 cases out of 1021 reports that referred to ICU devices. In the cases of malfunction, there was temporary harm in 38 events and more than temporary harm in five occurrences; in the events related to defective equipment, temporary harm was reported in 85 events and more than temporary harm was present in ten situation $\mathrm{s}^{(2)}$.

This type of information is corroborated by a multinational study about factors that compromise patient safety, which identified 112 equipment failures ${ }^{(10)}$. In Brazil, the concern about problems presented by apparatuses has been addressed by the Brazilian Policy for Management of Health Technologies, mainly the aspects regarding healthcare devices. It is understood that many of these pieces of equipment are underused or not used as a consequence of issues related to inadequate infrastructure, lack of training, insecurity or obsolescence of the equipment. These management aspects bring physical, economic, legal and social impacts and make the administration of these failures a challenge ${ }^{(11)}$.

As a result of the awareness of this issue, an effort to qualify the management of healthcare equipment has been undertaken to support the organization of regional healthcare networks in Brazil, the Quali-SUS network. An example is a study carried out in 2014 to diagnose management elements in healthcare networks in 15 Brazilian regions. A piece of data related to the equipment failure question is the fact that $64 \%$ of the devices in general hospitals and $73 \%$ of the apparatuses in teaching hospitals are submitted to preventive maintenance ${ }^{(11)}$.

It is considered that the evaluation of risks of use of these technologies by nurses is still infrequent ${ }^{(4)}$, although these professionals are fundamental in this process for understanding how equipmentrelated incidents happen. An investigation whose main goal was to analyze the handling of technologies by nurses that work at ICUs under the safety perspective revealed that many handling difficulties were related to failures in these devices. Taking into account the relevance of discussing this subject, emphasized in literature and public policies, the following question was formulated: "What equipment failures occur during handling by nurses and how do nurses behave when these failures happen?".

\section{OBJECTIVE}

To identify equipment failures during their handling by nurses and analyze the professionals' conducts before such problems.

\section{METHOD}

\section{Ethical aspects}

The project proposal was approved by the Research Ethics Committee where the investigation was performed and a Certificate of Submission for Ethical Appreciation. The participants signed a free and informed consent form and had their anonymity secured by being identified with the word Nurse and a number based on the order of observation.

\section{Theoretical-methodological framework}

The present study is part of a project which analyzed the conducts of nurses during handling of equipment in ICUs as regards the occurrence of errors and their repercussions in patients in terms of adverse events. The observational method was used and the investigated variables were data configuration, problem detection/solution, alarm handling, interruptions, interpretation of the meaning of the actions, etc.

There are several methods to conduct error and adverse event studies, each one with advantages and drawbacks. Studies of observation of patient care, with potential accuracy and precision, stand out for providing data otherwise unavailable and consequently detecting a higher number of active errors ${ }^{(12)}$. Because many active errors in the handling of equipment may be related to the device itself, the outcomes of the present investigation brought up equipment failures, a fact that justifies the choice of this methodological framework.

The theoretical framework to address the actions of nurses was the safety model proposed by James Reason in the context of the human error theory. This author drew on a systemic perspective, construing errors as an element inherent to the human condition; to promote safety, it is necessary to create systems that anticipate errors, that is, prevent their occurrence or eliminate the effects of the harm they originate ${ }^{(13)}$. Therefore, this model distinguishes active failures, made by people who are interacting with the system directly and that may be a slip, a lapse or a mistake, from latent conditions, which relate to decisions made in a high level of management. 
It is considered that the analysis of errors should focus on the subjacent conditions that make a mistake possible and that can be identified before it happens in detriment of active failures, centered on a person that can be blamed for them. The goal is to create obstacles to avoid that active and latent conditions align and originate an accident, leading to harm ${ }^{(13)}$.

\section{Study type}

Descriptive, exploratory and qualitative field research, which was carried out in 2014.

\section{Methodological procedures}

\section{Study setting}

The field of the investigation was the ICU of a public federal institution. It was chosen for convenience, because it is the place where the authors work as professors, and also for the potential quality as a data source, given that it concentrates a significant number of pieces of equipment that are used to provide life support to critical patients and where the occurrence of incidents of this kind impacts on their clinical evolution immediately.

\section{Data source}

The participants were nurses from the ICU of the examined institution, chosen according to the criteria of providing direct care to patients, working the day shift and being present on the field during the data production period. Nurses out of work for any reason were excluded. The total number of nurses in the day shift was nine; they had a 12-hour working day followed by a 60 -hour rest and made up three teams. Eight professionals met the inclusion criteria and one was out of work.

The choice of participants was justified by the fact that nurses are responsible for managing the handling and functioning of equipment, especially those used in monitoring, ventilation, and infusion. Although equipment failures can be identified at any time, the manipulation of the apparatuses is more frequent during the day, notably when patients are transported to do exams, which makes failures more common in this shift. This is the reason why data collection was restricted to this period of the day.

As for the care dynamics, nurses and nursing technicians were subdivided into the beds in the unit, assuming the responsibility for comprehensive care to patients, including handling equipment. The ICU had two areas: one aimed at patients with clinical pathologies, with eight beds, in which two nurses work directly, and one reserved for patients who require surgical interventions, under the command of one nurse and two nursing technicians.

\section{Data collection and organization}

Data were produced through two techniques: observation and interview. The former was based on a previously written script, which focused on the care situations that required the handling of equipment and during which failures could come up, mostly nonprogrammed interruptions of the equipment, battery discharge, disconnections, electric problems, and alarms. When failures were detected during handling, the measures adopted by the nurses were recorded.
These observations were registered on a logbook. The researchers took detailed notes of theoretical, narrative, methodological or personal nature, ipsis litteris, about the scenes that they saw, to confer density on them ${ }^{(14)}$. From these records, the researchers formulated a script with questions that led to the next step of the study, the interview one, oriented to the interpretation of the participants of the watched scenes.

The participants offered first-hand accounts about crucial points that referred to the occurrence of equipment failures identified by the researchers and the actions which succeeded them. This approach was carried out reservedly, after the care of patients. The interviews were registered as audio recordings for posterior transcription.

\section{Data analysis}

The observation data totaled 130 hours and were read by two independent researchers, who discussed the transcriptions in group meetings of the research group to make sense of the scenes. This analysis was based on a thick description ${ }^{(14)}$ of the material and supported the interpretation suggested by the authors.

The interview data went through an analytical deepening of their content ${ }^{(15)}$, in which the excerpts with explanations about the equipment failure situations were tracked.

Because the researchers remained in the place where the study was developed for a relatively long time, they could apprehend the feedback from the participants on the findings, which was part of the process of data interpretation. Hence, one of the validity criteria for qualitative research was met. There was a recurrence of accounts with data saturation in the information gathered in eight interviews, in comparison with the findings based on the logbook. The following themes came up: handling failures, design of the apparatuses, equipment functioning and strategies to deal with such problems.

Data are presented in contrast to emphasize the characterization of the main equipment failures, the reactions of nurses when faced with these setbacks and the understanding of the phenomena in question. The concepts of Reason's safety model ${ }^{(11)}$ were used to guide the interpretation and support discussion of situations with risk of harm to patients.

\section{RESULTS}

The testimonies of the nurses, when questioned on the handling of equipment from the perspective of patient safety, revealed the problems experienced in the routine of intensive care are recurrent.

These batteries are a problem [...] you cannot really trust these pieces of equipment, they also stop working by themselves. (Nurse 1)

Technology is fundamental for the quality of care these days, and it is our responsibility as nurses to know and explore this part; the devices can show problems, just as patients can become critical. (Nurse 6)

[...] I hope that they arrive soon [new monitors], because equipment failure and this terrible maintenance end up interfering with our work. (Nurse 7) 
These problems in equipment can be a defect or malfunction. In the latter situation, the registered scenes showed that it was especially common with infusion pumps. One of the recorded incidents took place during the preparation of an intravenous medication for the patient at bed 5 to control blood pressure. After placing the infusion pump next to the bed, nurse 7 tried to program the prescribed dose several times unsuccessfully, given that the display of the device showed an error message and/or exhibited a programming different from the aimed one. Unable to start the infusion, the professional went to the stock and got another pump, which worked properly. Nurse 7 sent the equipment to the nurse manager and requested it to be sent to evaluation and corrective maintenance. When back to the nursing station, the nurse said to the researcher:

These pumps are awful, right now I was trying to program the sodium nitroprusside dose and it [the infusion pump] would set the volume at 10 milliliters $[\mathrm{mL}] /$ hour[h] only. It was supposed to be just $1 \mathrm{~mL} / \mathrm{h}$, I set 1 , but when the equipment started it displayed $10 \mathrm{~mL} / \mathrm{h}$. I wonder what would happen if I had not seen it, these pumps go for maintenance, work for a week and then give trouble again! (Excerpt of logbook, 7:30 a.m. - 12:00 a.m., Nurse 7.)

This type of difficulty with the handling of equipment happened again when Nurse 8 assisted the medical team during a tracheostomy. After the planning and setting of all the necessary materials, the surgeon asked the nurse to perform a flush (fast infusion) of Fentanyl, because the patient was uneasy in bed. The nurse had trouble triggering the command with the flush function and obtained success only after the third attempt. After the surgical procedure, Nurse 8 discussed the fact with the nursing technician:

These pumps always leave us in the lurch! I was trying to press that button and it did not work. But it did, at last! (Excerpt of logbook, 7:30 a.m. - 12:00 a.m., Nurse 8.)

An equipment failure can relate to its design, which can impair the interaction with the professional that handles it and compromise its adequate use. It can be considered an equipment failure associated with improper design and that results in use errors.

An example of this kind of problem arose when Nurse 5 detected the emission of alarms by the monitor used in the patient at box 12 . During clinical examination, the professional realized that the alarm referred to a blood pressure of $210 \times 110 \mathrm{mmHg}$ and a heart rate of 133 beats per minute or bpm. The nurse then correlated these results with the infused intravenous medication and realized that the programmed dose of noradrenaline in the infusion pump was 10 milliliters per hour, when the prescribed dose was 1 milliliter per hour. After detecting the discrepancy in the rate of infusion of this vasoactive drug, the professional arranged its correction and subsequently talked to the nursing technician involved in the situation. (Excerpt of logbook, 7:30 a.m. - 12:10 a.m., Nurse 5.)

When one of the researchers asked the participants to explain the scenes that showed errors in the handling of the equipment, such as the one described in the excerpt above, they mentioned elements such as small screens, size of the buttons nonproportional to the size of their hands, and volume of the alarms as having potential to generate recurrent problems.

The possibilities of harm originated from defect and/or malfunction are real and get more evident when patients depend on equipment to keep their vital functions, as illustrated when the patient in bed 14 was moved to do a tomography of the abdomen; the person was 67 years old and was diagnosed with chronic kidney disease and hepatitis $\mathrm{C}$. The equipment taken during the transport were a portable fan, a transport monitor and an infusion pump. When the patient was being taken back to the bed, in the elevator, the fan battery discharged, which greatly concerned the team. Nurse 3 started the manual ventilation procedure, which lasted approximately ten minutes. The parameters of the patient when they arrived at the original unit were a blood pressure of $180 \times 100 \mathrm{mmHg}$ and a heart rate of $100 \mathrm{bpm}$. The artificial ventilation was then reconnected to the patient and the hemodynamic parameters stabilized. Nurse 3 headed to the managing room and after leaving it said to the researcher:

These things happen, unfortunately, the device indicated being complete charged but stopped! (Excerpt of logbook, 1 p.m. - 5:30 p.m., Nurse 3.)

As for the conducts of the nurses regarding the handling of equipment when failures happen, data analysis indicates that there is no planning for daily checking of the apparatuses or checking of their functioning during the work process. Consequently, nurses work on demand, that is, when a problem comes up, they try to solve it, which, in these situations, includes corrective maintenance.

We tried to charge it for reevaluation, and we hope it has not stopped working, because here maintenance is corrective only, and when a piece of equipment is taken to be repaired, it takes a long time for us to receive another one. It will be a problem and disturb the service. (Nurse 3)

Maintenance is corrective only. There is no other way to do it! Quite often the equipment comes back with the same problem, and we have to keep an eye on it. (Nurse 4)

The absence of a plan of action formulated by nurses at the ICU to deal with equipment failure resulted in the conduct to swap a device for another one whose functioning is proper and forward the old one to the maintenance sector. As a consequence, there is a risk to the care of patients, because the lack of periodic checking may result in a high number of devices with malfunction, decrease of the spare stock and a compromised service capacity in comparison with the demand. A situation experienced and reported by Nurse 7 illustrates this problem. The professional contacted the nursing manager to evaluate the monitor that was being used in the patient at bed 8 , because it was not registering the parameters of monitoring of arterial oxygen saturation and heart rate. After evaluating the equipment, the nursing manager replaced the wires attached to the monitor, but the problem persisted. Nurse 7 then said:

I do not know how long it has been like that. The monitor showed a warning about the impossibility to monitor breathing 
and cardiac function since the change of shift. (Excerpt of logbook, 7:30 a.m. - 12:10 a.m., Nurse 7.)

The nursing manager, in an attempt to solve the problem, searched the stock and brought a new monitor to replace the instrument. Last, she was concerned with the lack of stock of monitors, because the broken ones are not sent back to the unit. Nurse 7 concluded:

It is not possible to keep equipment in this situation, we will have to register it all! (Excerpt of logbook, 7:30 a.m. - 12:10 a.m., Nurse 7.)

\section{DISCUSSION}

The use of medical devices in the ICU setting is a mark of this care environment, involving equipment of different levels of complexity, ranging from noninvasive tools to machines that support life. Incidents during the use of this equipment and the complications that follow are a problem for safety and can originate from four types of interactions: patient - device, device - device, professional - device, and environment - device ${ }^{(16)}$.

It is claimed that these critical incidents related to medical devices are responsible for most incidents in ICUs and that the causes are inadequate training and defective equipment, that is, they originate from professional - device and device - device interaction ${ }^{(16)}$.

As for the interaction device - device, the problems identified in the equipment in the present study are similar to those observed in other critical areas, such as the issues in the field of anesthesia. The evaluation of adverse effects performed by the safety agency of the United Kingdom revealed 1,029 relevant incidents with anesthesia equipment from 2006 to 2008. The main categories of devices involved in the failures were monitors, fans, infusion pumps and anesthesia machines. These events had potential to cause harm, which was prevented by their quick detection and intervention by the team ${ }^{(17)}$.

In a study which listed the main cases of malfunction in equipment, the authors mentioned the frequency of incidents in ICUs and in the anesthesia area and, although they considered that the number of events decreased, there were cases that caused severe adverse effects in patients. The researchers claimed that the inadequate use is the main cause of problems, but stressed that the distinction between technical and human failure is artificial because the cause of harm is multifactorial ${ }^{(7)}$.

A set of small errors and defects originates a real problem that encompasses both professionals and equipment. For instance, equipment failure can be related to obsolescence, inadequate maintenance and lack of control before use. Incorrect handling can be the result of lack of attention, fatigue, negligence, ergonomic issues and insufficient training ${ }^{(7)}$.

One of the pieces of equipment whose data indicated problems was the infusion pump, mainly in the episodes in which Nurses 7 and 8 needed to set a command and the device exhibited malfunction. The concern about typical problems with infusion pumps such as the one described in the prior accounts is one of the items in the list of the ten most dangerous aspects related to the use of health technologies ${ }^{(18)}$. It encompasses the most common harms, which should be minimized with the management of the technologies. In 2014, medication errors related to infusion pumps were in the second position in the list; failures in this type of equipment or their inappropriate use are common and can generate significant harm to patients ${ }^{(18)}$.

Such relevance is observed in the survey about incidents with medical devices in patients during anesthesia procedures and at ICUs, whose outcomes are available in an international database. From 2005 to $2006,91 \%$ of the 4,188 registered incidents were classified as minor, most of them related to fabrication problems and involving mainly infusion equipment and disposable tools ${ }^{(1)}$.

In the analysis model used in the present investigation, latent errors are compared to resident pathogens which are similarly present in the system as a consequence of decisions by people responsible for its design. These decisions can create the conditions for mistakes to occur or originate weaknesses in the system that remain for a long time ${ }^{(12)}$.

The malfunction of the infusion pump mentioned by Nurses 7 and 8 could have resulted in the administration of a dose higher than the prescribed one, a delayed administration or the absence of it by a nurse, which constitutes an active mistake. This episode shows the need to analyze the conditions for the occurrence of errors of this type, which includes the management of equipment in the unit, a latent condition to the safety of patients who use these devices.

Management of medical care equipment is important to healthcare services, taking into consideration that the quality of care is significantly influenced by the proper functioning of this apparatus, from the economic, social and physical point of view. This process of management encompasses the acquisition phase, which refers to the evaluation of the need to include a technology, and maintenance, which involves technical and administrative actions to keep or put equipment into operation ${ }^{(11)}$.

Management of the maintenance of equipment is a set of actions to fix problems already detected and seek to identify potential failures that may cause harm to patients ${ }^{(11)}$. Maintenance is classified as corrective, preventive and predictive. The first category is executed occasionally, after a failure episode; the second class corresponds to the periodic and planned examination in accordance with the recommendations of the manufacturer, oriented to keep the equipment in good functioning conditions; the third type is flexible regarding scheduling, given that it is done from the identification of indicators or malfunction ${ }^{(11)}$.

The management also covers the making of an inventory with the identification and location of equipment and the reservation of devices with similar characteristics for replacement in case of failure or during maintenance, so the unit care routine is not compromised ${ }^{(7)}$. The use of a checklist and records of the evaluation of equipment have also been a useful strategy to reduce the risk of critical incidents since they guarantee the correct functioning of equipment before they are used. Violation of this procedure can impair patient safety ${ }^{(7)}$.

Another possibility in the management scope is the use of task analysis tools, in this case focused on the use of equipment, to describe the errors that may occur and the phase of the work process in which they will come up to formulate prevention actions and a strategy to evaluate results. 
One example is the tool for analysis of failure modes and their consequences (Failure Mode and Effect Analysis or FMEA), which defines an area of high risk, gathers the multidisciplinary team for the analysis of processes related to risks of failures and suggests actions to eliminate or control them ${ }^{(13)}$.

Equipment management takes form as a defensive barrier to strengthen the safety of the health system. Empirical data report actions and processes that break these barriers. In the results shown in the account of Nurse 3, it is evinced that, when a piece of equipment is sent to maintenance, its replacement takes time, which hinders the availability of the devices. It must be stressed that the maintenance in the examined sector is corrective only, and in many cases the devices are returned with the same problem, as illustrated by the testimonies of Nurses 3 and 4 .

This deficiency in the management of equipment may result in episodes like the one reported by Nurse 5, in which the mechanical ventilation tool stopped working when the team took the patient back to the ICU after a tomography scan, causing alterations in hemodynamic parameters. This inadequacy is mentioned by other nurses in studies that address the use of technologies in ICUs, such as the investigation about the perceptions of intensive care nurses of the relationship between care safety, humanity and use of equipment in the work process ${ }^{(19)}$.

One of the presented categories refers to the risk associated with the use of machines. Empirical data obtained through interviews point to the lack of equipment to replace those sent to maintenance or in situations of failure of ventilation and monitoring devices. Thus, the authors stress the importance of backup machines and preventive maintenance to prevent incidents similar to those identified in the accounts, which compromised patient safety ${ }^{(19)}$.

An analysis of literature shows that another branch of discussion related to equipment management is the professionals' health perspective. From this point of view, researchers studied the factors that affect the use of hard technology by nurses in a cardiology ICU and analyzed the psychophysical impacts on the health condition of professionals ${ }^{(20)}$.

From the testimonies of the nurses, complaints regarding the absence of technical services of supervision and preventive maintenance of the equipment were submitted, which arises questioning of the reliability of the data and concerns about the risks of adverse events. This results in suffering for workers and has consequences on their health ${ }^{(20)}$.

As for the practice of verification, different studies have pointed to the application of checklists before the use of equipment to promote safety and quality ${ }^{(8,21)}$, mainly in devices used in anesthesia procedures ${ }^{(7)}$. This subject is present in the paper that brings a reflection about the future of intensive care and lists five interventions that will revolutionize the quality of care in ICUs. In the prospection of a typical ICU by 2020, the authors emphasize that, to accomplish such revolution, it is necessary to overcome the traditional practice and learn with experiences from areas such as industry and aviation, which benefited from the quick progress of information technology. One of the interventions that should become common in the routine of ICUs by 2020 is the use of checklists, considered as a tool which helps to implement the practice based on evidence and that acts as a memory auxiliary, preventing errors ${ }^{(21)}$.
It is concluded that nurses, notably those in charge of the service management, should establish a partnership with the technical sector to implement actions to monitor equipment regarding the risk of adverse outcomes, focusing on prevention and observation of malfunction. Clinical nurses should have the duty of watch out for systematic monitoring and daily evaluation, with reporting of the devices with problems, combined with the management of this work process.

Another result that draws attention refers to the discrepancy between the infused dose of noradrenaline identified by Nurse 5 and the prescribed one, which may have been caused, among other reasons, by the design of the infusion pump. The role of equipment design has interested researchers that work on the perspective of patient safety because of the risk of adverse events it may present ${ }^{(22-23)}$. In accordance with the situation described during the handling of the infusion pump, studies stress types of errors in which design is a contributing factor, such as the investigation that reports the circumstance of use of defibrillators for cardiopulmonary resuscitation ${ }^{(22,24)}$. The professional used electrodes to monitor and defibrillate the patient, but selected the paddle mode for analysis of the heart rate, despite the fact that it was not being used. The monitor displayed the information corresponding to a cardiac arrest to which shock application is not advocated. After 13 minutes, the paddles were used and indicated ventricular fibrillation. Although resuscitation was carried out, early defibrillation was not performed and the patient suffered neurological harm ${ }^{(22)}$.

Emission of clinical alarms by equipment is a function that has also been analyzed from this standpoint. Many of these alarms are considered false, with no clinical meaning, and contribute to alarm fatigue, the desensitization of the team for important clinical alarms manifested in behaviors such as ignoring them, silencing them, turning them off or turning down their volume. This scenario has raised the interest of researchers to measure the time between stimulus and response of ICU professionals to equipment alarms ${ }^{(25-26)}$.

In one of these studies, $60 \%$ of the alarms in multiparameter monitors provoked a response time in the team longer than ten minutes, and were classified as fatigued ${ }^{(25)}$. Therefore, it is understood that alarm fatigue and its effects related to patient safety could be attenuated by applying principles of human factors engineering.

The recurrence of these situations has stressed the influence of design in equipment-related harm, mainly when the conception of the device is not aligned with the needs, cognitive processes and environments of users. In this regard, there is a current of thought suggesting that focusing interventions on repair recommendations, new policies and training is a short lasting and ineffective strategy, and advocating to concentrate efforts into the change of factors with higher sustainability ${ }^{(22)}$.

This perspective is corroborated by studies that point to the relevance of human factors engineering to analyze incidents involving equipment and propose strategies oriented to their prevention ${ }^{(27)}$. The logic behind these investigations matches the adopted theoretical framework, which seeks to overcome the approach centered at users ${ }^{(12)}$ and evaluate all the variables involved in the use of equipment, such as those related to the devices themselves, and organizational, environmental and individual aspects ${ }^{(4)}$.

According to this understanding and the interests of the nursing field, the nonalignment of infusion pumps' design to 
the principles of human factors engineering may have been a latent condition which caused the active error involving Nurse 5 during the determination of the noradrenaline dose.

It is important to emphasize that this latent condition is inserted in the field of management of health technologies, especially in the evaluation that aims to contribute to decision making about incorporation and monitoring of the use of medical devices and provide information about safety, benefits and costs of such apparatus to professionals and patients ${ }^{(28)}$.

One of the domains of this technology evaluation is the operational one, which focuses its analysis on variables associated with the performance of technology and the people who use it. One of these variables refers to human factors and ergonomics, which address abilities, limitations and other human characteristics that differ among people. Hence, usability is one of the human factors that should be taken into account in projects of equipment, including ease of use, effectiveness, efficiency, and user (professional) satisfaction ${ }^{(28)}$.

To prevent design-related equipment failure, it is important to organize defenses that make a system safe regarding equipment handling ${ }^{(11)}$. Nurses should participate in this management of technologies by providing information crucial to develop a better equipment design, which facilitates the interaction with professionals and the interpretation that they adopt of the outcomes given by devices ${ }^{(4)}$. From a practical standpoint, nurses should prepare reports based on their expertise and difficulties experienced during work addressing the evaluation of incorporated technologies regarding usability, encompassing graphical interface, transparency of operations, batteries, buttons, human and structural resources and avoiding the indication of equipment that offers risks to patient safety ${ }^{(4)}$.

This implies to create a safety culture which makes nurses worry about potential risks and real failures provoked by the use of equipment and show proactive commitment to the quality of the service and maintenance of a safe patient care environment ${ }^{(16)}$. These principles should be instilled from the beginning of professional training and reinforced during practice, through strategies applied in teamwork and in permanent education, in addition to evaluating production and availability of equipment and application of checklists ${ }^{(6,29)}$.

\section{Study limitations}

The present study was carried out in the ICU of one institution, a fact that reduces the coverage of the results and consequently their potential to be compared with other healthcare services.

\section{Contributions to the nursing field}

The findings stressed the need to implement a system of continuous monitoring by nurses that work in ICUs to prevent the occurrence of incidents with technologies and minimize risks to the public. The gathered information supports the proposal of an instrument of equipment verification encompassing identification, evaluation of autonomy of batteries and proper functioning, analysis of the graphical user interface, recording of identified potential problems, applied maintenance measures and a final classification by using a color code, in which green indicates correct functioning and liberation for use, yellow means attention by professionals regarding use with patients and red warns about the contraindication to operate the equipment.

\section{FINAL CONSIDERATIONS}

Technology is indispensable in the care of patients, but the multiple variables and constant changes involved in it give rise to the possibility of incidents, a risk inherent to its use. These events were evinced in the accounts of the present study, describing the malfunction of infusion pumps, user errors related to equipment design and issues with batteries of fans.

In this context, the management of health technologies assumes more relevance, mainly the administration of equipment materialized in the identification of the objects which offer risk and collection of information that supports decision making to minimize harm. However, the conducts of nurses reveal the lack of evaluation of medical devices and absence of preventive measures to avoid equipment failure.

Therefore, the authors recommend that technovigilance be reinforced in the examined healthcare setting to identify problems in equipment, whether they are defects, malfunction or inadequate project design, which may happen during their use and result in risks to patient safety. Technology management must analyze the factors that influence safety, such as infrastructure, team training, maintenance services and safety culture in the institution.

\section{FUNDING}

The present study was sponsored by the Carlos Chagas Filho Rio de Janeiro Research Foundation (FAPERJ, as per its acronym in Portuguese).

\section{REFERENCES}

1. Beydon L, Ledenmat PY, Soltner C, Lebreton F, Hardin V, Benhamou D, et al. Adverse events with medical devices in anesthesia and intensive care unit patients recorded in the French safety database in 2005-2006. Anesthesiol[Internet]. 2010 [cited 2016 May 31];112(2):364-72. Available from: http://anesthesiology.pubs.asahq.org/article.aspx?articleid = 1932751

2. Thomas AN, Galvin I. Patient safety incidents associated with equipment in critical care: a review of reports to the UK National Patient Safety Agency. Anaesth[Internet]. 2008[cited 2016 May 31];63(11):1193-7. Available from: http://onlinelibrary.wiley.com/ doi/10.1111/j.1365-2044.2008.05607.x/full

3. Elpern E, Killeen K, Patel G, Senecal PA. The application of intermittent pneumatic compression devices for thromboprophylaxis: an observational study found frequent errors in the application of these mechanical devices in ICUs. Am J Nurs[Internet]. 2013[cited 2016 May 31];113(4):30-6. Available from: https://www.ncbi.nlm.nih.gov/pubmed/23492806

4. Mattox E. Medical devices and patient safety. Crit Care Nurse[Internet]. 2012[cited 2016 May 31];32(4):60-8. Available from: http:// 
ccn.aacnjournals.org/content/32/4/60.full.pdf + html

5. Russel RA, Murkowski K, Scanlon MC. Discrepancies between medication orders and infusion pump programming in a pediatric intensive care unit. Qual Saf Health Care[Internet]. 2010[cited 2016 May 31];19:S31-5. Available from: http://qualitysafety.bmj. com/content/19/Suppl_3/i31.long

6. Ribeiro GSR, Silva RC, Ferreira MA. Technologies in intensive care: causes of adverse events and implications to nursing. Rev Bras Enferm[Internet]. 2016[cited 2017 May 21];69(5):972-80. Available from: http://www.scielo.br/pdf/reben/v69n5/en_0034-7167reben-69-05-0972.pdf

7. Bourgain JL, Coisel Y, Kern D, Nouette-Gaulain K, Panczer M. What are the main "machine dysfunctions" to know? Ann Fr Anesth Reanim[Internet]. 2014[cited 2016 May 31];33(7-8):466-71. Available from: http://www.sciencedirect.com/science/article/pii/ S0750765814009940

8. Silva R, Amante LN. Checklist for the intrahospital transport of patients admitted to the intensive care unit. Texto Contexto Enferm[Internet]. 2015[cited 2016 May 31];24(2):539-47. Available from: http://www.scielo.br/pdf/tce/v24n2/0104-0707-tce-24-02-00539.pdf

9. Duarte SCM, Stipp MAC, Silva MM, Oliveira FT. Adverse events and safety in nursing care. Rev Bras Enferm[Internet]. 2015[cited 2016 May 31];68(1):144-54. Available from: http://www.scielo.br/pdf/reben/v68n1/en_0034-7167-reben-68-01-0144.pdf

10. Valentin A, Capuzzo M, Guidet B, Moreno RP, Dolanski L, Bauer P. Patient safety in intensive care: results from the multinational Sentinel Events Evaluation (SEE) study. Intens Care Med[Internet]. 2006[cited 2016 May 31];32(10):1591-8. Available from: http:// link.springer.com/article/10.1007\%2Fs00134-006-0290-7

11. Brasil. Ministério da Saúde. Secretaria de Ciência Tecnologia e Insumos Estratégicos. Mapeamento e diagnóstico da gestão de equipamentos médico-assistenciais nas regiões de atenção à saúde do projeto QualiSUS-Rede. Brasília: Ministério da Saúde; 2016.

12. Vincent C. Segurança do paciente: orientações para evitar eventos adversos. São Caetano do Sul: Yendis; 2009.

13. Reason J. Human errors: model sand management. BMJ[Internet]. 2000[cited 2016 May 31];320(7237):768-70. Available from: https://www.ncbi.nlm.nih.gov/pmc/articles/PMC1117770/pdf/768.pdf

14. Geertz C. A interpretação das culturas. Rio de Janeiro: LTC; 2008.

15. Vaismoradi M, Turunen $\mathrm{H}$, Bondas T. Content analysis and thematic analysis: Implications for conducting a qualitative descriptive study. Nurs Health Sci[Internet]. 2013[cited 2016 May 31];15(3):398-405. Available from: http://onlinelibrary.wiley.com/doi/10.1111/ nhs.12048/full

16. Rossi PJ, Edmiston Jr CE. Patient safety in the critical care environment. Surg Clin North Am[Internet]. 2012 [cited 2016 May 31];92(6):1369-86. Available from: http://www.sciencedirect.com/science/article/pii/S0039610912001570

17. Cassidy J, Smith A, Arnot-Smith J. Critical incident reports concerning anesthetic equipment: analysis of the UK National Reporting and Learning System (NRLS) data from 2006-2008. Anaesthesia[Internet]. 2011[cited 2016 May 31];66(10):879-88. Available from: http://onlinelibrary.wiley.com/doi/10.1111/j.1365-2044.2011.06826.x/full

18. ECRI Institute. Know the health technology hazards that pose possible patient risk. OR Man[Internet]. 2014 [cited 2016 May 31];30(2):1-4. Available from: http://www.ormanager.com/wp-content/uploads/2014/02/ORM_0214_p.18_ECRI.pdf

19. Mendes RNC, Carmo AFS, Haddad MCL, Rossaneis MA. Nurses perceptions about the use of equipment in the intensive care unit. Rev Enferm UFPE[Internet]. 2014[cited 2016 May 31];8(7):1904-11. Available from: https://periodicos.ufpe.br/revistas/ revistaenfermagem/article/view/9865/0

20. Oliveira EB, Souza NVM. Estresse e inovação tecnológica em unidade de terapia intensiva de cardiologia: tecnologia dura. Rev Enferm UERJ[Internet]. 2012[cited 2016 May 31];20(4):457-62. Available from: http://www.e-publicacoes.uerj.br/ojs/index.php/ enfermagemuerj/article/view/4768/3519

21. Bauman KA, Hyzy RC. ICU 2020: Five interventions to revolutionize quality of care in the ICU. J Intens Care Med[Internet]. 2014[cited 2016 May 31];29(1):13-21. Available from: http://jic.sagepub.com/content/29/1/13.full.pdf + html

22. Fairbanks RJ, Wears RL. Hazards with medical devices: the role of design. Ann Emerg Med[Internet]. 2008 [cited 2016 May 31];52(4):519-21. Available from: https://www.ncbi.nlm.nih.gov/pubmed/18722693

23. Borycki E. Trends in health information technology safety: from technology-induced errors to current approaches for ensuring technology safety. Health Inform Res[Internet]. 2013[cited 2016 May 31];19(2):69-78. Available from: http://synapse.koreamed. org/DOlx.php?id=10.4258/hir.2013.19.2.69

24. Samaranayake NR, Cheung ST, Chui WC, Cheung BM. Technology-related medication errors in a tertiary hospital: a 5-year analysis of reported medication incidents. Int J Med Inform[Internet]. 2012 [cited 2016 May 31];81(12):828-33. Available from: http://www. sciencedirect.com/science/article/pii/S1386505612001761

25. Bridi AC, Silva RCL, Farias CCP, Franco AS, Santos VLQ. Reaction time of a health care team to monitoring alarms in the intensive care unit: implications for the safety of seriously ill patients. Rev Bras Ter Intens[Internet]. 2014[cited 2016 May 31];26(1):28-35. Available from: http://dx.doi.org/10.5935/0103-507X.20140005

26. Perghera AK, Silva RCL. Stimulus-response time to invasive blood pressure alarms: implications for the safety of critical-care patients. Rev Gaúcha Enferm[Internet]. 2014[cited 2016 May 31];35(2):135-41. Available from: http://dx.doi.org/10.1590/1983-1447.2014.02.43715 
27. Hyman WA. Human factors: should your medical devices require intensive care? Crit Care Nurs Clin North Am[Internet]. 2010[cited 2016 May 31];22(2):233-41. Available from: http://www.sciencedirect.com/science/article/pii/S0899588510000122

28. Brasil. Ministério da Saúde. Secretaria de Ciência, Tecnologia e Insumos Estratégicos. Diretrizes Metodológicas: elaboração de estudos para avaliação de equipamentos médico-assistenciais. Brasília: Ministério da Saúde; 2014.

29. Wegner W, Silva SC, Kantorski KJC, Predebon CM, Sanches MO, Pedro ENR. Education for culture of patient safety: implications to professional training. Esc Anna Nery Rev Enferm[Internet]. 2016[cited 2017 Mar 29];20(3):e20160068. Available from: http:// www.scielo.br/pdf/ean/v20n3/en_1414-8145-ean-20-03-20160068.pdf 